sphincter. Of course in the absence of anatomical examination, no direct proof of the presence of a sphincter is possible.

All the points considered make out a strong case for the condition here being looked upon as one of genuine secondary pupil.

My thanks are due to Mr. Arthur Zorab, surgeon to the Southampton Eye Hospital, for permission to show the case.

\title{
NOTE ON RECORDING VISUAL ACUITY
}

BY

\section{G. F. Alexander, Major R.A.M.C.}

IN the annotation on visual requirements of soldiers in THE British JOURNAL OF OPHThalmology of January, 1918, I am troubled, though not surprised, to read the statement that " the practice of regarding $6 / 18$ as $1 / 3$ of normal vision, and so on, cannot

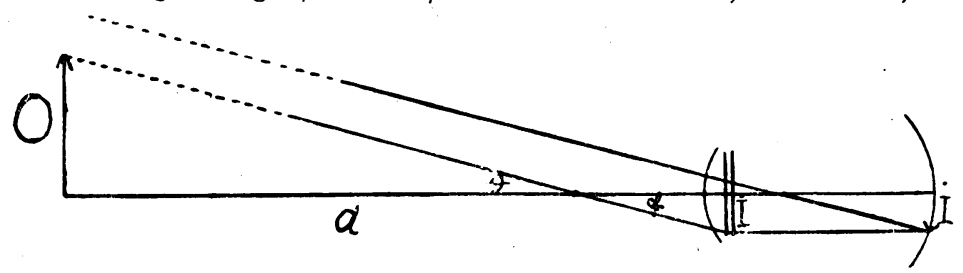

be too strongly condemned." Why should it be condemned ? It is perfectly correct, the contrary view being an error which might with advantage be abandoned.

(1) In Snellen's types the letters in all of the lines are constructed so as to subtend the same angle, viz., $5^{\prime}$ at the distance marked for the line they are in, $6 \mathrm{M}, 9 \mathrm{M}, 12 \mathrm{M}$, etc., hence if $\mathrm{O}$ be the size of any letter and $\mathrm{D}$ the distance at which this angle is subtended by it $\mathrm{O}$ varies directly as $\mathrm{D}$.

(2) In the accompanying diagram if $O$ be any object, $d$ its distance from the anterior focus of the eye, $\theta$ the angle subtended by $\mathrm{O}$ at this point, i.e., the visual angle, $\mathrm{f}$ the anterior focal length of the eye, and $I$ the image of $\mathrm{O}$, as $\mathrm{I}=\mathrm{f} \tan \theta, \mathrm{i}=\mathrm{f} \frac{\mathrm{O}}{\mathrm{d}}$ hence, granted that the visual acuity, $\mathrm{V}$ varies inversely as $\mathrm{i}, \mathrm{V}$ varies directly as $\mathrm{d}$ and inversely as $\mathrm{O}$, i.e., from (1) inversely as $\mathrm{D}$, so that if $\mathrm{V}$ of $6 / 6$ be taken as normal or unity, $\mathrm{V}$ of $6 / 9,6 / 12,6 / 18$, etc., accurately expresses $2 / 3 \mathrm{~V}, 1 / 2 \mathrm{~V}, 1 / 3 \mathrm{~V}$, etc.

It may be objected that Snellen takes the visual angle as being that subtended at the nodal point, $\mathrm{N}$, and not the anterior focus of the eye, but as the rays from the letters enter the eye parallel the the visual angle is the same in either case. 